\title{
The Historically Evolving Impact of the Ogallala Aquifer: Agricultural Adaptation to Groundwater and Drought
}

\author{
Richard Hornbeck and Pinar Keskin
}

Online Appendices: Figures, Tables, Proofs 


\section{Appendix Figure 1. Ogallala Boundary and Soil Group Control Variables}

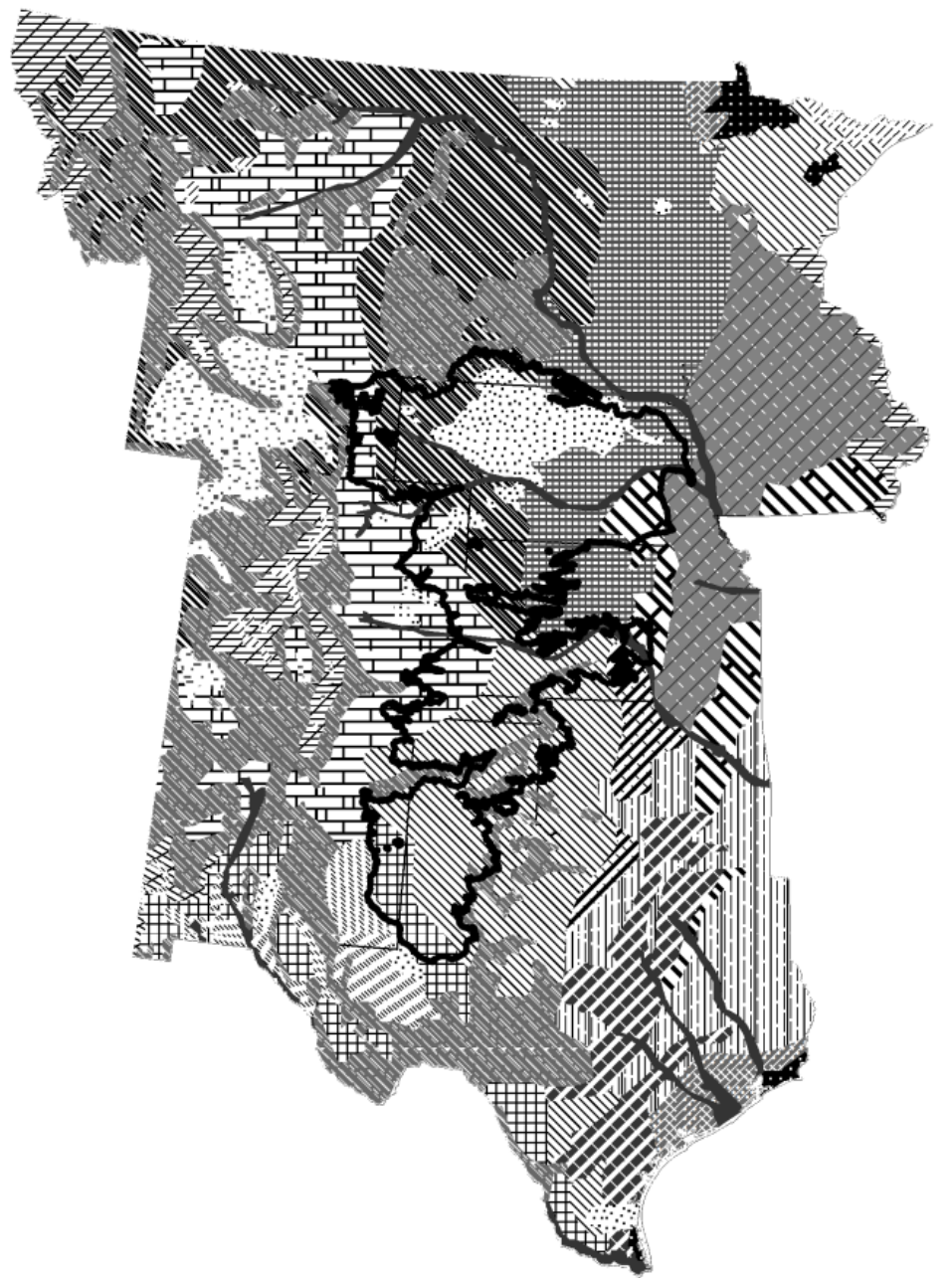

\section{Soil Groups appearing within Ogallala}

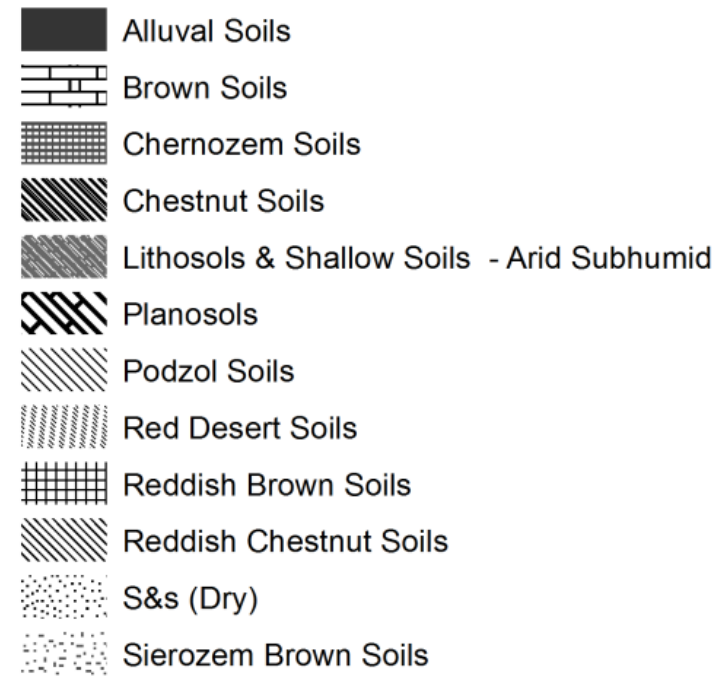

Other Soil Groups

Bing Bog Soils

7/7 Gray - Brown Podzolic Soils

Q. Prairie Soils

|in|

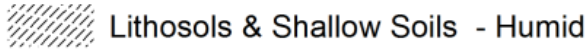

Noncalcic Brown Soils

WYIF, Reddish Soils

848. Rendzina Soils

Wiesenböden \& Ground Water

Podzol \& Half-Bog Soils

Notes: The Ogallala boundary (USGS) is overlaid with major soil groups, as mapped by the Soil Conservation Service (SCS 1951). 


\section{Appendix Figure 2. Ogallala Boundary and Natural Vegetation Regions}
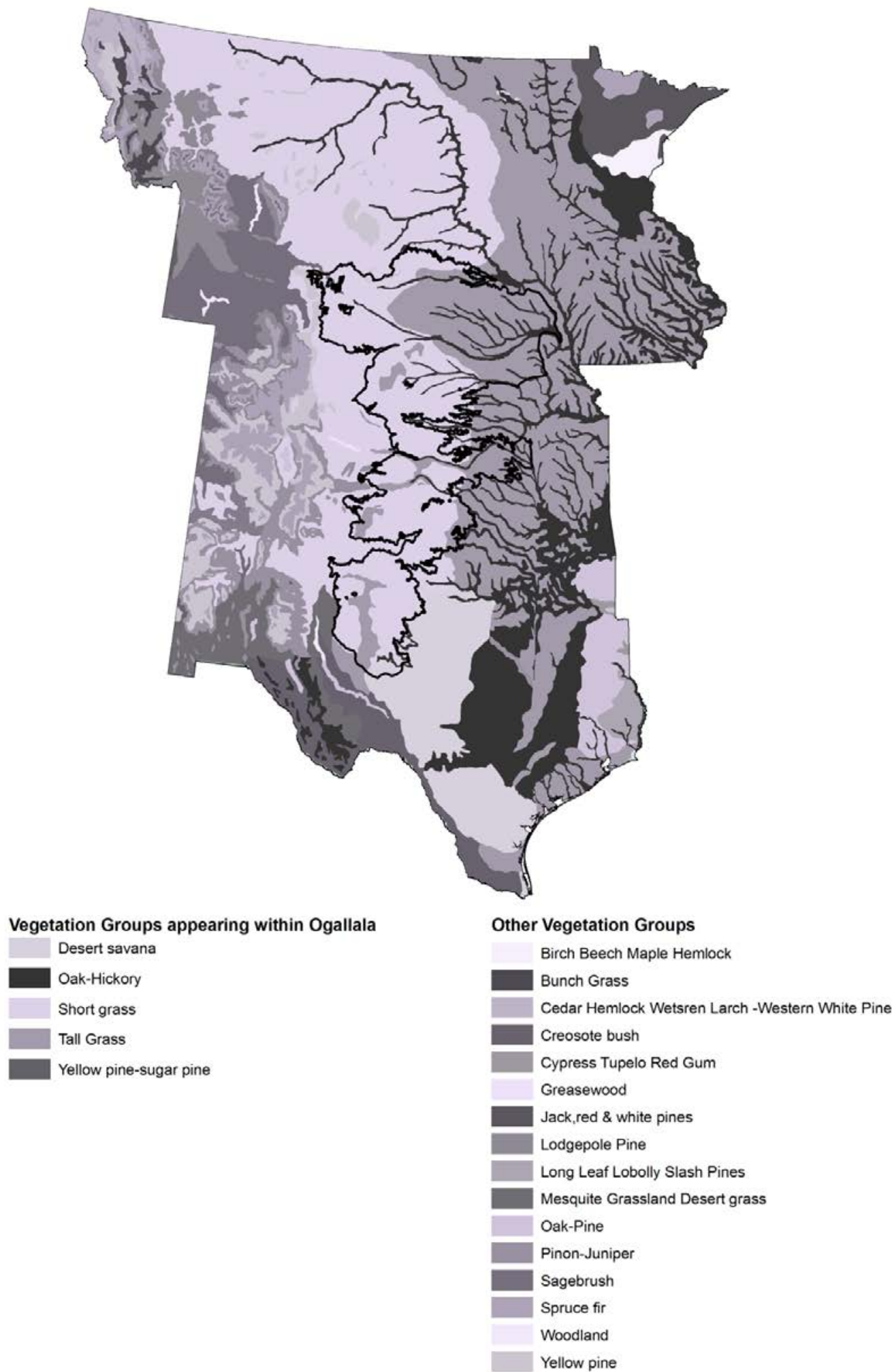

Notes: The Ogallala boundary (USGS) is overlaid with natural vegetation regions, as mapped by the 1924 Atlas of Agriculture (USDA 1924). 
Appendix Table 1. Estimated Local Spillover Impacts: Nearby Non-Ogallala Counties vs. Counties 100km from the Ogallala

\begin{tabular}{|c|c|c|c|c|c|c|c|c|}
\hline & \multicolumn{2}{|l|}{ Irrigated } & \multicolumn{2}{|c|}{ Corn Acres Harvested } & \multicolumn{2}{|c|}{ Wheat Acres Harvested } & \multirow{2}{*}{$\begin{array}{c}\text { Log Farm } \\
\text { Value }\end{array}$} & \multirow{2}{*}{$\begin{array}{l}\text { Log Farm } \\
\text { Revenue }\end{array}$} \\
\hline & Farmland & Farmland & Irrigated Corn & All Corn & Irrigated Wheat & All Wheat & & \\
\hline Coefficient in era: & $(1)$ & $(2)$ & (3) & (4) & (5) & (6) & (7) & (8) \\
\hline \multirow[t]{2}{*}{ 1920-1945 } & 0.001 & 0.066 & -0.0000 & 0.021 & -0.0004 & 0.023 & 0.259 & 0.136 \\
\hline & $(0.006)$ & $(0.044)$ & $(0.0004)$ & $(0.014)$ & $(0.0009)$ & $(0.016)$ & $(0.182)$ & $(0.198)$ \\
\hline \multirow[t]{2}{*}{$1950-1974$} & -0.002 & -0.016 & 0.0038 & 0.013 & -0.0003 & -0.002 & 0.037 & 0.008 \\
\hline & $(0.010)$ & $(0.048)$ & $(0.0027)$ & $(0.016)$ & $(0.0002)$ & $(0.017)$ & $(0.129)$ & $(0.210)$ \\
\hline \multirow[t]{2}{*}{ 1978-2002 } & 0.002 & 0.035 & 0.0125 & 0.003 & -0.0005 & -0.010 & 0.068 & 0.150 \\
\hline & $(0.012)$ & $(0.051)$ & $(0.0079)$ & $(0.013)$ & $(0.0013)$ & $(0.021)$ & $(0.111)$ & $(0.253)$ \\
\hline Sample Counties & 136 & 136 & 114 & 133 & 99 & 135 & 136 & 136 \\
\hline
\end{tabular}

Notes: For counties with zero area over the Ogallala, each column reports estimates from a modified version of equation (3) in the text. The coefficients report the impact of "Negative Distance to Ogallala Boundary," measured in 100km units, which reflects average outcomes in counties next to the Ogallala boundary relative to counties $100 \mathrm{~km}$ away. Otherwise, the specifications are as described in Tables 2-4. Data for some outcome variables are only available in some years (shown in

Figures 5-8). Robust standard errors clustered by county are reported in parentheses. ** denotes statistical significance at the $1 \%$ level, * at the $5 \%$ level. 


\section{Theory Appendix}

This appendix contains proofs of the theoretical results discussed in section II.

\section{I.A Model Setup}

The maximization problem of our representative farmer is

$$
\max _{L_{1}, L_{2}, w_{1}, w_{2}} y_{1}\left(L_{1}, w_{1}, d\right)+y_{2}\left(L_{2}, w_{2}, d\right)
$$

subject to the constraints

$$
\begin{aligned}
& w_{1}+w_{2}=\bar{w} \\
& L_{1}+L_{2}=\bar{L}
\end{aligned}
$$

The production functions are globally concave, with five additional assumptions:

1. The marginal product of water is higher for the first crop:

$$
\partial y_{1} / \partial w_{1}>\partial y_{2} / \partial w_{2}>0
$$

2. The marginal product of water declines slower for the first crop:

$$
\partial^{2} y_{2} /\left(\partial w_{2}\right)^{2}<\partial^{2} y_{1} /\left(\partial w_{1}\right)^{2}<0
$$

3. Water and land are complementary for both crops, but weakly more so for the first crop:

$$
\partial^{2} y_{1} / \partial L_{1} \partial w_{1} \geq \partial^{2} y_{2} / \partial L_{2} \partial w_{2}>0
$$

4. Drought decreases the productivity of land for both crops, but drought has a larger negative effect on the water-intensive crop:

$$
\partial^{2} y_{1} / \partial L_{1} \partial d<\partial^{2} y_{2} / \partial L_{2} \partial d<0
$$

5. Drought increases the productivity of water for both crops, but more so for the waterintensive crop:

$$
\partial^{2} y_{1} / \partial w_{1} \partial d>\partial^{2} y_{2} / \partial w_{2} \partial d>0
$$




\section{I.B Comparative Statics Without Drought}

Initially, suppress the impact of drought $(d)$ on production. The first order conditions for the farmer's maximization problem are given by:

$$
\begin{aligned}
& \frac{\partial y_{1}\left(L_{1}^{*}, w_{1}^{*}\right)}{\partial w_{1}}-\frac{\partial y_{2}\left(\bar{L}-L_{1}^{*}, \bar{w}-w_{1}^{*}\right)}{\partial w_{2}}=0 \\
& \frac{\partial y_{1}\left(L_{1}^{*}, w_{1}^{*}\right)}{\partial L_{1}}-\frac{\partial y_{2}\left(\bar{L}-L_{1}^{*}, \bar{w}-w_{1}^{*}\right)}{\partial L_{2}}=0 .
\end{aligned}
$$

Of interest is how optimal factor allocation responds to a change in the available water $(\bar{w})$. Proposition 1. Water and land allocated to the water intensive crop are increasing in total water availability.

Proof Totally differentiating the first order conditions with respect to $\bar{w}$, we obtain

$$
\begin{aligned}
& \frac{\partial^{2} y_{1}(\cdot)}{\partial w_{1} \partial L_{1}} \frac{\partial L_{1}^{*}}{\partial \bar{w}}+\frac{\partial^{2} y_{1}(\cdot)}{\left(\partial w_{1}\right)^{2}} \frac{\partial w_{1}^{*}}{\partial \bar{w}}-\frac{\partial^{2} y_{2}(\cdot)}{\left(\partial w_{2}\right)^{2}}\left(1-\frac{\partial w_{1}^{*}}{\partial \bar{w}}\right)+\frac{\partial y_{2}(\cdot)}{\partial w_{2} \partial L_{2}} \frac{\partial L_{1}^{*}}{\partial \bar{w}}=0, \text { and } \\
& \frac{\partial^{2} y_{1}(\cdot)}{\partial w_{1} \partial L_{1}} \frac{\partial w_{1}^{*}}{\partial \bar{w}}+\frac{\partial^{2} y_{1}(\cdot)}{\left(\partial L_{1}\right)^{2}} \frac{\partial L_{1}^{*}}{\partial \bar{w}}+\frac{\partial^{2} y_{2}(\cdot)}{\left(\partial L_{2}\right)^{2}} \frac{\partial L_{1}^{*}}{\partial \bar{w}}-\frac{\partial y_{2}(\cdot)}{\partial w_{2} \partial L_{2}}\left(1-\frac{\partial w_{1}^{*}}{\partial \bar{w}}\right)=0 .
\end{aligned}
$$

Rewriting, we obtain

$$
\begin{aligned}
& {\left[\frac{\partial^{2} y_{1}(\cdot)}{\partial w_{1} \partial L_{1}}+\frac{\partial y_{2}(\cdot)}{\partial w_{2} \partial L_{2}}\right] \frac{\partial L_{1}^{*}}{\partial \bar{w}}+\left[\frac{\partial^{2} y_{1}(\cdot)}{\left(\partial w_{1}\right)^{2}}+\frac{\partial^{2} y_{2}(\cdot)}{\left(\partial w_{2}\right)^{2}}\right] \frac{\partial w_{1}^{*}}{\partial \bar{w}}=\frac{\partial^{2} y_{2}(\cdot)}{\left(\partial w_{2}\right)^{2}}, \text { and }} \\
& {\left[\frac{\partial^{2} y_{1}(\cdot)}{\partial w_{1} \partial L_{1}}+\frac{\partial y_{2}(\cdot)}{\partial w_{2} \partial L_{2}}\right] \frac{\partial w_{1}^{*}}{\partial \bar{w}}+\left[\frac{\partial^{2} y_{1}(\cdot)}{\left(\partial L_{1}\right)^{2}}+\frac{\partial^{2} y_{2}(\cdot)}{\left(\partial L_{2}\right)^{2}}\right] \frac{\partial L_{1}^{*}}{\partial \bar{w}}=\frac{\partial^{2} y_{2}(\cdot)}{\partial w_{2} \partial L_{2}}}
\end{aligned}
$$

The solution to this system is

$$
\begin{aligned}
\frac{\partial L_{1}^{*}}{\partial \bar{w}} & =\frac{\left(\frac{\partial^{2} y_{1}(\cdot)}{\left(\partial w_{1}\right)^{2}}+\frac{\partial^{2} y_{2}(\cdot)}{\left(\partial w_{2}\right)^{2}}\right) \frac{\partial y_{2}(\cdot)}{\partial w_{2} \partial L_{2}}-\left(\frac{\partial^{2} y_{1}(\cdot)}{\partial w_{1} \partial L_{1}}+\frac{\partial y_{2}(\cdot)}{\partial w_{2} \partial L_{2}}\right) \frac{\partial^{2} y_{2}(\cdot)}{\left(\partial w_{2}\right)^{2}}}{\left(\frac{\partial^{2} y_{1}(\cdot)}{\left(\partial w_{1}\right)^{2}}+\frac{\partial^{2} y_{2}(\cdot)}{\left(\partial w_{2}\right)^{2}}\right)\left(\frac{\partial^{2} y_{1}(\cdot)}{\left(\partial L_{1}\right)^{2}}+\frac{\partial^{2} y_{2}(\cdot)}{\left(\partial L_{2}\right)^{2}}\right)-\left(\frac{\partial^{2} y_{1}(\cdot)}{\partial w_{1} \partial L_{1}}+\frac{\partial y_{2}(\cdot)}{\partial w_{2} \partial L_{2}}\right)^{2}} \\
\frac{\partial w_{1}^{*}}{\partial \bar{w}} & =\frac{\left(\frac{\partial^{2} y_{1}(\cdot)}{\left(\partial L_{1}\right)^{2}}+\frac{\partial^{2} y_{2}(\cdot)}{\left(\partial L_{2}\right)^{2}}\right) \frac{\partial^{2} y_{2}(\cdot)}{\left(\partial w_{2}\right)^{2}}-\left(\frac{\partial^{2} y_{1}(\cdot)}{\partial w_{1} \partial L_{1}}+\frac{\partial y_{2}(\cdot)}{\partial w_{2} \partial L_{2}}\right) \frac{\partial y_{2}(\cdot)}{\partial w_{2} \partial L_{2}}}{\left(\frac{\partial^{2} y_{1}(\cdot)}{\left(\partial w_{1}\right)^{2}}+\frac{\partial^{2} y_{2}(\cdot)}{\left(\partial w_{2}\right)^{2}}\right)\left(\frac{\partial^{2} y_{1}(\cdot)}{\left(\partial L_{1}\right)^{2}}+\frac{\partial^{2} y_{2}(\cdot)}{\left(\partial L_{2}\right)^{2}}\right)-\left(\frac{\partial^{2} y_{1}(\cdot)}{\partial w_{1} \partial L_{1}}+\frac{\partial y_{2}(\cdot)}{\partial w_{2} \partial L_{2}}\right)^{2}}
\end{aligned}
$$

Global concavity of the revenue function $\left(y_{1}+y_{2}\right)$ ensures that the denominators in $\partial L_{1}^{*} / \partial \bar{w}$ and $\partial w_{1}^{*} / \partial \bar{w}$ are positive. Under assumptions $1-3$, above, the numerators are also positive. Thus, $\partial L_{1}^{*} / \partial \bar{w}>0$ and $\partial w_{1}^{*} / \partial \bar{w}>0$. 


\section{I.C General Case: Comparative Statics With Drought}

Proposition 2. When the land allocation is held constant, an increase in water availability reduces the (negative) impact of drought:

$$
\frac{\mathrm{d}}{\mathrm{d} \bar{w}}\left[\frac{\partial y_{1}\left(L_{1}^{*}, w_{1}^{*}(\bar{w}), d\right)}{\partial d}+\frac{\partial y_{2}\left(L_{2}^{*}, w_{2}^{*}(\bar{w}), d\right)}{\partial d}\right]>0 .
$$

Conversely, when the land allocation can respond to changes in $\bar{w}$, an increase in water availability has an ambiguous effect on the impact of drought.

Proof Consider the effect of $\bar{w}$ on the derivative of the revenue function with respect to $d$.

$$
\begin{aligned}
& \frac{\mathrm{d}}{\mathrm{d} \bar{w}}\left[\frac{\partial y_{1}}{\partial d}+\frac{\partial y_{2}}{\partial d}\right]=\frac{\partial^{2} y_{1}}{\partial d \partial L_{1}} \frac{\partial L_{1}^{*}}{\partial \bar{w}}+\frac{\partial^{2} y_{1}}{\partial d \partial w_{1}} \frac{\partial w_{1}^{*}}{\partial \bar{w}}-\frac{\partial^{2} y_{2}}{\partial d \partial L_{2}} \frac{\partial L_{1}^{*}}{\partial \bar{w}}+\frac{\partial^{2} y_{2}}{\partial d \partial w_{2}} \frac{\partial w_{2}^{*}}{\partial \bar{w}} \\
& =\underbrace{\left(\frac{\partial^{2} y_{1}}{\partial d \partial w_{1}} \frac{\partial w_{1}^{*}}{\partial \bar{w}}+\frac{\partial^{2} y_{2}}{\partial d \partial w_{2}} \frac{\partial w_{2}^{*}}{\partial \bar{w}}\right)}_{>0}+\underbrace{\left(\frac{\partial^{2} y_{1}}{\partial d \partial L_{1}}-\frac{\partial^{2} y_{2}}{\partial d \partial L_{2}}\right) \frac{\partial L_{1}^{*}}{\partial \bar{w}}}_{<0}
\end{aligned}
$$

Assumption 5 and Proposition 1 imply that the first term is positive. Assumption 4 and Proposition 1 imply that the second term is negative. Thus, an increase in water availability has an ambiguous effect on the impact of drought. If the land allocation is held fixed $\left(\partial L_{1}^{*} / \partial \bar{w}=0\right)$, then the impact is unambiguously positive. In addition, the effect of water availability on the impact of drought is more positive than when the land allocation is free to adjust.

\section{I.D Special Case: Comparative Statics With Drought}

Consider the special case of constant returns to land, in which the farmer maximizes

$$
L_{1} y_{1}\left(w_{1}, d\right)+L_{2} y_{2}\left(w_{2}, d\right)
$$

Proposition 3. When the production technology displays constant returns to land:

1. If the land allocation can adjust to $\bar{w}$, then an increase in water availability increases the (negative) impact of drought:

$$
\frac{\mathrm{d}}{\mathrm{d} \bar{w}}\left[L_{1}^{*}(\bar{w}) \frac{\partial y_{1}\left(w_{1}^{*}(\bar{w}), d\right)}{\partial d}+L_{2}^{*}(\bar{w}) \frac{\partial y_{2}\left(w_{2}^{*}(\bar{w}), d\right)}{\partial d}\right]<0 .
$$

2. If the land allocation is fixed, then an increase in water availability reduces the (negative) impact of drought. 
Proof The first order conditions simply to:

$$
\begin{aligned}
\frac{\partial y_{1}\left(w_{1}, d\right)}{\partial w_{1}} & =\frac{\partial y_{2}\left(w_{2}, d\right)}{\partial w_{2}} \\
y_{1}\left(w_{1}, d\right)-y_{2}\left(w_{2}, d\right) & =\frac{\partial y_{2}\left(w_{2}, d\right)}{\partial w_{2}}\left(w_{1}-w_{2}\right) .
\end{aligned}
$$

Assumption 1 and global concavity imply that

$$
w_{1}^{*}>w_{2}^{*}
$$

In deriving the impact of $\bar{w}$, total differentiation of the first order conditions yields:

$$
\begin{aligned}
\frac{\partial^{2} y_{1}\left(w_{1}, d\right)}{\left(\partial w_{1}\right)^{2}} \frac{\partial w_{1}}{\partial \bar{w}} & =\frac{\partial^{2} y_{2}\left(w_{2}, d\right)}{\left(\partial w_{2}\right)^{2}} \frac{\partial w_{2}}{\partial \bar{w}} \\
\frac{\partial y_{1}\left(w_{1}, d\right)}{\partial w_{1}} \frac{\partial w_{1}}{\partial \bar{w}}-\frac{\partial y_{2}\left(w_{2}, d\right)}{\partial w_{2}} \frac{\partial w_{2}}{\partial \bar{w}} & =\frac{\partial^{2} y_{2}\left(w_{2}, d\right)}{\left(\partial w_{2}\right)^{2}} \frac{\partial w_{2}}{\partial \bar{w}}\left(w_{1}-w_{2}\right)+\frac{\partial y_{2}\left(w_{2}, d\right)}{\partial w_{2}}\left(\frac{\partial w_{1}}{\partial \bar{w}}-\frac{\partial w_{2}}{\partial \bar{w}}\right) .
\end{aligned}
$$

Using the first order conditions to simply the second expression:

$$
\frac{\partial^{2} y_{2}\left(w_{2}, d\right)}{\left(\partial w_{2}\right)^{2}} \frac{\partial w_{2}}{\partial \bar{w}}\left(w_{1}-w_{2}\right)=0
$$

Because $w_{1}^{*} \neq w_{2}^{*}$, the only solution is $\partial w_{1} / \partial \bar{w}=\partial w_{2} / \partial \bar{w}=0$. That is, increased water availability does not cause the farmer to use more water per acre; instead, the farmer shifts land toward the more water-intensive crop. Because $w_{1}$ and $w_{2}$ are constants,

$$
L_{1}^{*}(\bar{w})=\frac{\bar{w}-w_{2}}{w_{1}-w_{2}}
$$

and $L_{1}^{*}$ is increasing in $\bar{w}$. Substituting this special case into the general solution:

$$
\begin{aligned}
& \frac{\mathrm{d}}{\mathrm{d} \bar{w}}\left[L_{1}^{*}(\bar{w}) \frac{\partial y_{1}}{\partial d}+L_{2}^{*}(\bar{w}) \frac{\partial y_{2}}{\partial d}\right]=\frac{\partial L_{1}^{*}}{\partial \bar{w}} \frac{\partial y_{1}}{\partial d}+L_{1}^{*} \frac{\partial^{2} y_{1}}{\partial d \partial w_{1}} \frac{\partial w_{1}^{*}}{\partial \bar{w}}+\frac{\partial L_{2}^{*}}{\partial \bar{w}} \frac{\partial y_{2}}{\partial d}+L_{2}^{*} \frac{\partial^{2} y_{2}}{\partial d \partial w_{2}} \frac{\partial w_{2}^{*}}{\partial \bar{w}} \\
& =\underbrace{\left(L_{1}^{*} \frac{\partial^{2} y_{1}}{\partial d \partial w_{1}} \frac{\partial w_{1}^{*}}{\partial \bar{w}}+L_{2}^{*} \frac{\partial^{2} y_{2}}{\partial d \partial w_{2}} \frac{\partial w_{2}^{*}}{\partial \bar{w}}\right)}_{=0}+\underbrace{\left(\frac{\partial y_{1}}{\partial d}-\frac{\partial y_{2}}{\partial d}\right) \frac{\partial L_{1}^{*}}{\partial \bar{w}}}_{<0} .
\end{aligned}
$$

Thus, when land allocations can adjust and the production technology displays constant returns to land, an increase in water availability increases the (negative) impact of drought. If the land allocation is fixed, however, increased water availability can only be allocated on the intensive margin and the (negative) impact of drought declines. 